fixed. When the filament (which in the latest form is of tungsten) is glowing, a current will flow if an E.M.F. is applied between the negative terminal of the filament and the metal plate; the current can flow from the filament to the plate, but not in the reverse direction, and thus rectification results. Owing to the upward trend of the conductivity curve a much higher sensibility is obtained by applying a certain constant E.M.F. on which that due to the oscillations is superimposed. Passing to the question of the spark, the lecturer reproduced some interesting records showing how greatly the secondary current is increased when the spark gap is subjected to an air blast. Finally, Prof. Fleming showed his new form of spark discharger. This is of the Wien "quenched-spark" type, and consists of two heavy steel circular discs, one above the other, very perfectly surfaced and with an air gap of $\frac{1}{4} \mathrm{~mm}$. between them. The lower disc is stationary and the upper one is rotated. The discs are placed in oil, and as there is a hole in the lower disc there is a continual circulation of oil. The discharger is found to give very satisfactory and uniform results, and has been used for measuring losses in condensers.

Mr. R. W. Paul gave several demonstrations of kinematograph diagrams. One series, due to Prof. R. W. Wood, illustrated sound waves; but certainly the most effective films were those due to Prof. S. P. Thompson, F.R.S., showing the movement of lines of force as a keeper approaches a magnet, the starting of a current in a solenoid, the rotation of a dynamo armature (in section), and other similar phenomena. These must have appealed strongly to teachers of magnetism.

As regards the apparatus exhibited, it may be said that there were many interesting new instruments, though perhaps nothing very striking, and there was much excellence in many exhibits that were not essentially novel. Thus in optical work A. Hilger, Ltd., gave an excellent display of spectroscopic instruments and a beautiful demonstration of anomalous dispersion. R. and J. Beck showed a small spectroscope giving large dispersion and with a sine motion so as to give wave-lengths direct. Carl Zeiss, as usual, gave an interesting exhibit, including the movement of gold particles (stated to be about $6 \mu \mu$ in size) in colloidal solution, a special "cardioid" condenser being used, consisting of two lenses combined, and so shaped that a top illumination is secured for a dark ground, although the beam of light comes from below the centre of the stage. Messrs. E. Leitz showed a large projection apparatus giving excellent definition.

Photometric apparatus was not so much in evidence as on former occasions, but R. and J. Beck, and also Everett, Edgcumbe and Co., showed very small portable photometers for measuring surface brightness and illumination. As an exhibit of general interest may be mentioned that of Strange and Graham illustrating flapping flight. Two wings are worked by "Vilcar" mechanism, and a distinct upward pull is noticeable, apparently due to the upward path of the wing differing from that on the downward stroke.

The largest number of exhibits, as usual, were electrical. Several interesting thermo-electric exhibits were shown by the Cambridge Scientific Instrument Co., among which may be mentioned an arrangement for keeping the cold junction of a clinical recording thermometer at a constant temperature. This junction is covered by a small Dewar vacuum vessel, and is surrounded by a heating coil, which comes into action as soon as the temperature falls below a certain value; by this means the temperature of this junction is maintained constant to $0 \cdot I^{\circ} \mathrm{C}$. This firm also showed compensating leads consisting of copper and coppernickel alloy; these are run in series with the pyrometer, and, being thermo-electrically equal to the platinum/ platinum-iridium couple, they transfer the cold junction of the pyrometer to the galvanometer, thus securing less variation in temperature of the cold junction. An arrangement whereby a constant E.M.F. is obtained for applying to a pyrometer so as to secure a false zero was also shown, and we noticed a convenient piece of apparatus for tracing recalescence curves; also an improved form of C. T. R. Wilson's tilting gold-leaf electroscope. A new form of radiation pyrometer which does not require focussing was shown by the Foster Instrument Co., who also exhibited some special thermo-junction alloys. H. Tinsley and Co. NO. 2 I 47 , VOL. 85$]$ showed a set of instruments largely due to Dr. C. V. Drysdale, and some interesting vector diagrams of alternating magnetic flux in an iron wire, obtained by Drysdale's alternate-current potentiometer. This firm also showed a simple and strong form of vibration galvanometer based on the familiar Kelvin galvanometer; a heavy permanent magnet is provided for the control, and the tuning is effected (without affecting the zero) by magnetically shunting this magnet to the desired extent. The alternating current traverses a small coil, which can be easily changed, and the makers state that the instrument can be used for alternating pressures down to I/looth micro-volt. R. W. Paul exhibited a well-designed new type of decade standard resistance box with switch contacts, the case being filled with oil, and we noticed some new transforming apparatus by Leslie Miller and by Muirhead and Co. Since there were thirty-five exhibitors, we need scarcely say that there was a good deal to be seen, but in the above notes we have only been able to refer very briefly to a few of the more interesting items.

\section{INVESTIGATIONS ON WHEAT IN INDIA.'}

THE importance of the wheat crop in India is not always realised at home. Until the last few years we received more wheat from India than from Canada or Australia-sometimes more than from both countries put together. At the present time wheat represents some 7 per cent. of the total value of merchandise exported from India, but the amount exported is only about onetenth of the total production, the remaining nine-tenths being consumed in the country itself. When an industry has reached such great dimensions without excessive nursing it is clear that those engaged in it have consciously or unconsciously adopted tolerably satisfactory methods of working, and any attempt on the part of an outsider to effect improvements must be developed cautiously. When in Igo6 the Indian Board of Agriculture decided to take up the matter seriously, they entrusted the work to $\mathrm{Mr}$. and Mrs. Howard, and subsequent events have amply justified the wisdom of their choice. Several important papers have been issued, and finally a volume, "Wheat in India," in which the authors summarise the present position of the problem and indicate the lines on which advancement may be hoped for.

$\mathrm{Mr}$. and Mrs. Howard devote the first half-dozen chapters of their volume to a general sketch of wheatgrowing in India. Wheat is fairly widely distributed over the country, but the areas where it is really important all lie to the north or on the Central Plateau above the Ghats. In the north-west a great deal of the wheat is irrigated; the Punjab is especially well suited to canal irrigation by reason of its never-failing snow-fed rivers and its level tracts of land, but recourse is also had to irrigation by wells. On the other hand, in the Central Provinces, Bengal, and Bombay, only a small area is artificially watered.

In general, the soil is thoroughly well ploughed or scarified during the monsoon and previous to sowing, as many as fourteen ploughings being sometimes given. A good deal of manure is applied in the northern districts, but usually to the maize crop preceding the wheat; in the Central Provinces the monsoon (kharif) crop of rice, which precedes wheat, is slightly manured, but in Bombay the irrigated wheat itself is manured. Harvest begins in the Central Provinces in March, elsewhere in April, May, and even the end of June in the frontier districts. The wheat for export has to be got to Karachi for shipment as soon as possible, or it rapidly deteriorates, and is attacked by moths and weevils. In the rush the railway resources are heavily taxed, just as they are in Canada: the Indian case is, indeed, the worse, as there is no elevator system.

These preliminary chapters are illustrated by maps, 1 "The Milling and Baking Qualities of Indian Wheat." No. 2. By Albert Howard and Gabrielle L. C. Howard.

"The Influence of Envirnment on the Milling land Baking Qualities of Wheat in India." By. Albert Howard, H. M. Leake and Gabrielle L. C. Howard. (Pusa: Agricultural Research Institute.)

"Wheat in India, its Production, Varieties and Improvements." By Albert Howard"and Gabrielle L. C. Howard. Pp. ix +288 . (Calcutta : Thacker, Spink and Co. London: W. Thacker and Co., n.d.) 
quotations and statistics, and give an illuminating account of wheat-growing in India.

Passing on to a discussion of experimental work, the authors point out that manurial trials on orthodox lines are of purely academic interest in India. It was no doubt an excellent thing to make them, but their value is limited by the fact that the cultivator cannot usually buy the necessary manures. It is much more to the point to make cultivation trials, seeing that labour is very cheap and the labourer realises the necessity for working the land. But here again intelligent planning is necessary; if the trials are to serve as demonstrations for the native they must be made with implements he can afford to buy and learn to handle, and which the village blacksmith can repair. A summary is given of the well-known Cawnpore experiments, which show that the nitrogen supply is the limiting factor in normal conditions of moisture and temperature obtaining there. At Nagpur nitrogen was also the most important factor, but the water supply was in this case near the limit. The Punjab irrigation experiments, said to be the best of their kind in India, were made to ascertain the best quantity of water and the best number of vaterings. It was found that the native was, like many other irrigation farmers, taking too much water, so that the area under treatment was needlessly curtailed, and the revenue suffered loss. But the authors further point out that over-watering gives rise to mottled grain and to samples uneven in texture, and therefore of low value. This loss in value, of course, falls on the cultivator himself, and if it could be brought home to him would, no doubt, induce him to take less water.

The authors then discuss the factors adversely affecting the production of wheat in India. In order of merit these are climatic extremes, fungi, insects, and vermin. Of the diseases, rusts are the most important, transcending in effect all other diseases put together. The only trustworthy remedy at present known is to grow rust-resisting varieties. Introduction of such wheats of high repute from abroad proved to be useless; wheats resistant in Australia succumbed badly in India, and, indeed, were more susceptible than the indigenous kinds, besides ripening too late. It therefore became necessary to raise new varieties from Indian wheats, and this work was begun by the authors in 1905. The first step was to take stock of the native sorts. An ordinary Indian wheat-field contains a mixture of several sub-varieties, which had to be isolated. These in turn comprise several types, agriculturally distinct, though botanically identical, and within each type individual variations occur. Selection. was carried on, not on the old mass-selection lines, but by isolating single plants and studying their progeny in succeeding generations. The separation of forms and of pure lines has been successfully accomplished, and already several wheats have been obtained which are of much greater value than the mixtures at present in cultivation. Indeed, five of the Pusa selections have been shown by milling and baking tests to be in the same class with the Canadian spring wheats, the strongest and most valuable on the market. When the botanical survey was well on to completion it was possible to hybridise. This work is now in hand, and it is to be hoped that $\mathrm{Mr}$. and Mrs. Howard will be able to carry the hybridisation on for the necessary length of time, so that the full benefit of their survey and selection work may be obtained.

A list of the botanical varieties of wheat found in India is then given, and for certain provinces the agricultural varieties as well. This survey is still in progress.

Throughout the book and the papers which the authors have issued the various wheat problems of India are handled in a masterly way. The record of work done reflects the highest credit on the authors, and is full of promise for the future of Indian agriculture.

THE REDUCTION OF ROLLING IN SHIPS.

$\mathrm{R}$ EFERENCE is made in Engineering for December 16 $\mathrm{R}$ to a paper by Mr. H. Frahm at the November meeting of the Schiffbautechnische Gesellschaft, in which the author describes his apparatus for reduction of rolling in ships. In this apparatus two water tanks are disposed on opposite sides of the centre line of the ship near the shell, and are connected below by a water conduit and above by an air conduit; a throttle valve is inserted in the latter. The water tanks are filled partly with water, which may oscillate in the closed circuit formed by the conduits. If the throttle valve is closed oscillation is practically prevented; with the valve full open the oscillations are unobstructed, excepting that free waves cannot arise.

The principle on which the device is based is that a series of wave-impulses will cause the ship to oscillate about its longitudinal axis; these oscillations will become pronounced when the period of the waves agrees with that of the natural vibration of the ship. These differ in phase by $90^{\circ}$, i.e. the maximum deflection of the ship from the vertical will occur a quarter period after the wave has been at its maximum inclination to the ship. The same applies to the oscillations of the ship and to those of the water column in the tanks, which rises and falls so that the two oscillation periods are equal, provided the water has the proper mass. In this case the oscillations of the water column will lag a quarter period behind those of the ship, and hence half a period behind the period of the waves, and the two turning moments acting on the ship will therefore oppose one another. This is an application of the principle of resonance.

Mr. Frahm's apparatus is beyond the mere experimental stage. The oil-tank boat W83 of the German Navy, 446 tons displacement, is a very stiff boat, with a high natural vibration period of 10.75 per minute. In dock the deflections from the perpendicular were reduced from $10^{\circ}$ to $2^{\circ}$ by twelve oscillations when the tanks were cut out, and by two oscillations with the tanks in action. At sea the amplitude of rolling was diminished to one-third. Two steamers of the Hamburg-America Line-the Ypirango and Corcovado-of 12,600 tons displacement, have been fitted with the anti-rolling tanks. The former was a notorious roller. Both are now regarded as steady boats; the tanks reduce rolling $\mathrm{II}^{\circ}$ (on either side) to $2 \frac{12^{\circ}}{2}$ maximum. Messrs. Blohm and Voss are designing anti-rolling tanks for the new passenger steamer of 55,000 tons which they are now building for the HamburgAmerica Line. The paper in itself is very interesting, and is doubly so in view of statements made recently in the case of the loss of the British steamer Waratah.

\section{ARGENTINE METEOROLOGICAL RESEARCH}

THE services rendered to meteorology by Dr. W. S.

Bruce in founding the meteorological observatory at Scotia Bay, South Orkneys, in 1903, are brought into forcible evidence by the publication of successive years observations. Through the exertions of Dr. Escalante, Minister of Agriculture, and the enthusiasm of Mr. W. G. Davis, the Argentine Meteorological Office was enabled to take over the observatory from the Scottish National Antarctic Expedition, and has maintained it ever since. It must be remembered that this is the only permanent meteorological observatory in Antarctic regions. The observations for 1904 , with an introduction by $\mathrm{Mr}$. R. C. Mossman, are now published, though the title-page is dated igo5. The observations of following years seem not yet to have appeared, but they are briefly summarised in a most interesting and useful outline by Mr. W. G. Davis on the climate of the Argentine Republic. It may be mentioned, also, that a discussion by Mr. Mossman of each successive year's observations has appeared year by year in the Scottish Geographical Magazine. The tardy appearance of the 1904 volume detracts somewhat from its interest in view of our knowledge of the six later years, but we understand that circumstances beyond the contro of the Meteorological Office alone delayed the publication.

Previous to the expedition of the Scotia it was supposed that, from their latitude, the South Orkneys would enjoy an oceanic climate. Actually, however, these conditions only obtain for four months, while for the rest of the year the conditions are continental. In exceptional years either of these states of climate may be prolonged at the expense of the other. The climate largely depends on the distribution of ice in the Weddell Sea. The average mean

1 Anales de Ja Oficina Meteorológica Argentina. Tomo xvi., Observaciones de las Islas Orcadas en el Año 1904. Text in both Spanish and English. (Buenos Aires, r905.)

"Climate of the Argentine Republic." By W. G. Davis. (Buenos Aires : Department of Agriculture, roro.) 